OPEN ACCESS

Edited by:

Mohammad Amjad Kamal,

King Abdulaziz University, Saudi Arabia

Reviewed by:

Michal Novak,

Slovak Academy of Sciences (SAS),

Slovakia

Domenico De Berardis,

Azienda UsI Teramo, Italy

${ }^{*}$ Correspondence:

Tapan K. Khan

tkhan@hsc.wvu.edu

Specialty section: This article was submitted to

Neurodegeneration,

a section of the journal

Frontiers in Neuroscience

Received: 04 December 2017 Accepted: 09 April 2018

Published: 30 April 2018

Citation:

Khan TK (2018) An Algorithm for Preclinical Diagnosis of Alzheimer's

Disease. Front. Neurosci. 12:275.

doi: 10.3389/fnins.2018.00275

\section{An Algorithm for Preclinical Diagnosis of Alzheimer's Disease}

\author{
Tapan K. Khan* \\ Center for Neurodegenerative Diseases, Blanchette Rockefeller Neurosciences Institute, West Virginia University, \\ Morgantown, WV, United States
}

Almost all Alzheimer's disease (AD) therapeutic trials have failed in recent years. One of the main reasons for failure is due to designing the disease-modifying clinical trials at the advanced stage of the disease when irreversible brain damage has already occurred. Diagnosis of the preclinical stage of $A D$ and therapeutic intervention at this phase, with a perfect target, are key points to slowing the progression of the disease. Various AD biomarkers hold enormous promise for identifying individuals with preclinical $A D$ and predicting the development of $A D$ dementia in the future, but no single $A D$ biomarker has the capability to distinguish the $A D$ preclinical stage. A combination of complimentary $A D$ biomarkers in cerebrospinal fluid ( $A \beta_{42}$, tau, and phosphor-tau), non-invasive neuroimaging, and genetic evidence of $A D$ can detect preclinical $A D$ in the in-vivo ante mortem brain. Neuroimaging studies have examined region-specific cerebral blood flow (CBF) and microstructural changes in the preclinical $A D$ brain. Functional $\mathrm{MRI}$ (fMRI), diffusion tensor imaging (DTI) MRI, arterial spin labeling (ASL) MRI, and advanced PET have potential application in preclinical AD diagnosis. A well-validated simple framework for diagnosis of preclinical $A D$ is urgently needed. This article proposes a comprehensive preclinical AD diagnostic algorithm based on neuroimaging, CSF biomarkers, and genetic markers.

Keywords: Alzheimer's disease, neuroimaging (anatomic and functional), CSF, diagnosis, differential, preclinical Alzheimer's disease

\section{INTRODUCTION}

Therapeutic interventions for Alzheimer's disease (AD) will have a better chance of success if initiated at the earliest stage (preclinical), before the synaptic loss and neuronal death occur. Therefore, an effective disease-modifying clinical trial should target the stage before the manifestation of clinical symptoms of memory loss and cognitive impairment. The term preclinical $\mathrm{AD}$ is initially described to classify cognitively normal individuals with evidence of amyloid plaques and hyperphosphorylated tau (p-tau) tangles (hallmarks of AD pathology) at time of brain autopsy (Hubbard et al., 1990). This definition of preclinical AD was built on the existing AD mechanistic hypothesis. Several longitudinal studies predicted the conversion of mild cognitive impairment (MCI) to $\mathrm{AD}$ when there is amyloid plaques and p-tau tangles in the brain (Petersen et al., 1999, 2001; Grand et al., 2011). In preclinical familial AD cases, Fox et al. (1999) were the first to use serial structural magnetic resonance imaging (MRI) to detect cerebral atrophy in a longitudinal study of asymptomatic individuals (no cognitive impairment) at high risk of the familial AD (autosomal dominant early-onset before 65 years of age). Since that study, several groups have examined the predictive capacity of various brain biomarkers, such as noninvasive neuroimaging 
modalities, and invasive cerebrospinal fluid (CSF) biomarkers $\left(\mathrm{A} \beta_{42}\right.$, tau, and $\mathrm{p}$-tau). These studies concluded that patients who are positive for various $\mathrm{AD}$ biomarkers in the preclinical $\mathrm{AD}$ stage are at higher risk of progressing to AD dementia (Mintun et al., 2006; Villemagne et al., 2008; Johnson et al., 2012; Dubois et al., 2016). Non-invasive neuroimaging modalities, such as positron emission tomography (PET), functional MRI (fMRI), diffusion tensor imaging (DTI) MRI, and arterial spin labeling (ASL) MRI hold enormous promise for identifying preclinical AD (Mintun et al., 2006; Mosconi et al., 2006; Villemagne et al., 2008; Johnson et al., 2012; Ewers et al., 2013; Dubois et al., 2016) (Table 2). CSF biomarkers can predict decreasing cognitive ability in studies of conversion of MCI to AD (Frölich et al., 2017) and predicting memory deficit in longitudinal studies of normal individuals (Fagan et al., 2007; Gustafson et al., 2007; Stomrud et al., 2007; Jansen et al., 2015). AD is a multifactorial disease with several genetic biomarkers are found to be involved (http://www.alzgene.org) in the pathogenesis of AD. Those genes increase the predictability of conversion of preclinical AD to MCI and finally AD. In this perspective review, we describe the utility of combining neuroimaging, CSF, and genetic $\mathrm{AD}$ biomarker in the diagnosis of preclinical $\mathrm{AD}$ and propose a comprehensive preclinical AD diagnostic algorithm.

\section{Preclinical Stage of Alzheimer's Disease}

The National Institute on Aging and Alzheimer's Association (NIA-AA) (2011) introduced the concept of "preclinical AD" that arises before MCI and advanced stages of $\mathrm{AD}$. The most recent definition of preclinical $\mathrm{AD}$, proposed in a joint meeting of NIA-AA and the International Working Group (IWG) in 2015 (Dubois et al., 2016), is the simplest: preclinical AD starts the day that pathological $\mathrm{AD}$ lesions appear without any clinical symptoms. The NIA-AA guideline (2011) divides the progression of $\mathrm{AD}$ into distinct phases, taking into account both $\mathrm{AD}$ pathobiology and clinical symptoms: preclinical, asymptomatic pre-dementia; symptomatic pre-dementia (MCI); and dementia due to AD (McKhann et al., 2011; Sperling et al., 2011). Before that, preclinical stage AD biomarkers were categorized as Stage 1: amyloidosis by PET and CSF $\mathrm{A} \beta_{42}$ analysis, and Stage 2: Neurodegeneration by PET and CSF tau (Jack et al., 2010). The preclinical phase can also be separated into "pre-symptomatic" and "asymptomatic at risk" suggested by IGW-2014 (Dubois et al., 2014). The pre-symptomatic preclinical AD refers to individuals with familial $\mathrm{AD}$ who will develop $\mathrm{AD}$ in the future. Individuals with pre-symptomatic preclinical $\mathrm{AD}$ show no clinical symptoms but have at least one mutation in the familial AD genes (APP, PSEN1, PSEN2). Asymptomatic at risk refers to preclinical $\mathrm{AD}$ in individuals without clinical symptoms, but positive for $\mathrm{AD}$ biomarkers (decreased level of $A \beta_{42}$, increased the level of tau $\mathrm{p}$-tau in CSF) or positive in A $\beta$-PET (Dubois et al., 2014). According to the NIA-AA (2011) progressive preclinical $\mathrm{AD}$ pathological trajectory can be divided into three distinguishable stages: in the first stage, there is evidence of abnormality in $A \beta$, and individuals in this stage would be positive for $A \beta$, no dementia or neurodegeneration. The second stage consists of positive for $A \beta$, plus higher CSF tau (neurodegeneration). In the third stage, individuals begin exhibiting evidence of memory problems along with abnormalities in CSF biomarkers and neuroimaging, but all evidence of memory problems is less than MCI cases (Sperling et al., 2011).

\section{CRITICAL EVALUATION OF IGW AND NIA-AA PRECLINICAL ALZHEIMER'S DISEASE CRITERIA}

$\mathrm{AD}$ pathology is a continuum process spanning many years of underlying changes in brain morphology due to preclinical $\mathrm{AD}$ stage to a clinical $\mathrm{AD}$ phase. Hippocampus volume loss, temporoparietal hypometabolism, and neocortical $A \beta$ deposition are the first to be affected in brain areas due to preclinical $\mathrm{AD}$ pathology. Metabolic brain networks of these areas are affected by age as well as by preclinical AD. White matter brain network is the primary area that is also affected in preclinical $\mathrm{AD}$. On the cellular level, the synaptic and the axonal degenerations start to occur, but such degenerations would not affect the overall memory at the preclinical AD stage. The critical point is how and when the in-vivo AD-related pathology that determines preclinical $\mathrm{AD}$ can be measured by AD-biomarkers. The revised IWG definition of a preclinical AD: no clinical sign of $\mathrm{AD}$ but has at least one positive pathological AD biomarker (Dubois et al., 2016). In a critical viewpoint, it will be very difficult to distinguish preclinical $\mathrm{AD}$ by only one AD-biomarker. On the other hand, the NIA-AA definition of preclinical $\mathrm{AD}$ is more generalized (not specific): evidence of amyloidosis and neurodegeneration (Sperling et al., 2011). Here also we need the more specific definition of the role and applicability of AD in-vivo pathological biomarkers. The revised IWG definition of preclinical $\mathrm{AD}$ is too simplified to find the right condition to diagnose preclinical AD. Therefore, neither of them are perfect for determining in-vivo preclinical $\mathrm{AD}$ by AD pathological biomarkers. Both IGW and NIA-AA definition of preclinical AD considered amyloidosis ahead of tauopathy. There is evidence that neurodegeneration due to high tau or tauopathy started before amyloidosis (Jack and Holtzman, 2013; Jack et al., 2013). The phenomenon of mixed pathologies (AD with non-AD dementia) underlying the preclinical AD stage of neurodegeneration has been completely ignored by both (IGW and NIA-AA) the definitions of preclinical AD.

\section{HYPOTHETICAL MODEL OF PRECLINICAL ALZHEIMER'S DISEASE AND PROGRESSION OF ALZHEIMER'S DISEASE}

A hypothetical model of $\mathrm{AD}$ progression in relation to aging and disease severity is shown in Figure 1. The disease severity increases as age increases, because age is the most important risk factor for $\mathrm{AD}$ dementia. Two trajectories of $\mathrm{AD}$ progression are shown, one based on changes in brain morphology (red) and the other is the onset of clinical symptoms of neurodegeneration (blue). Neurodegeneration due to normal aging is shown as a 


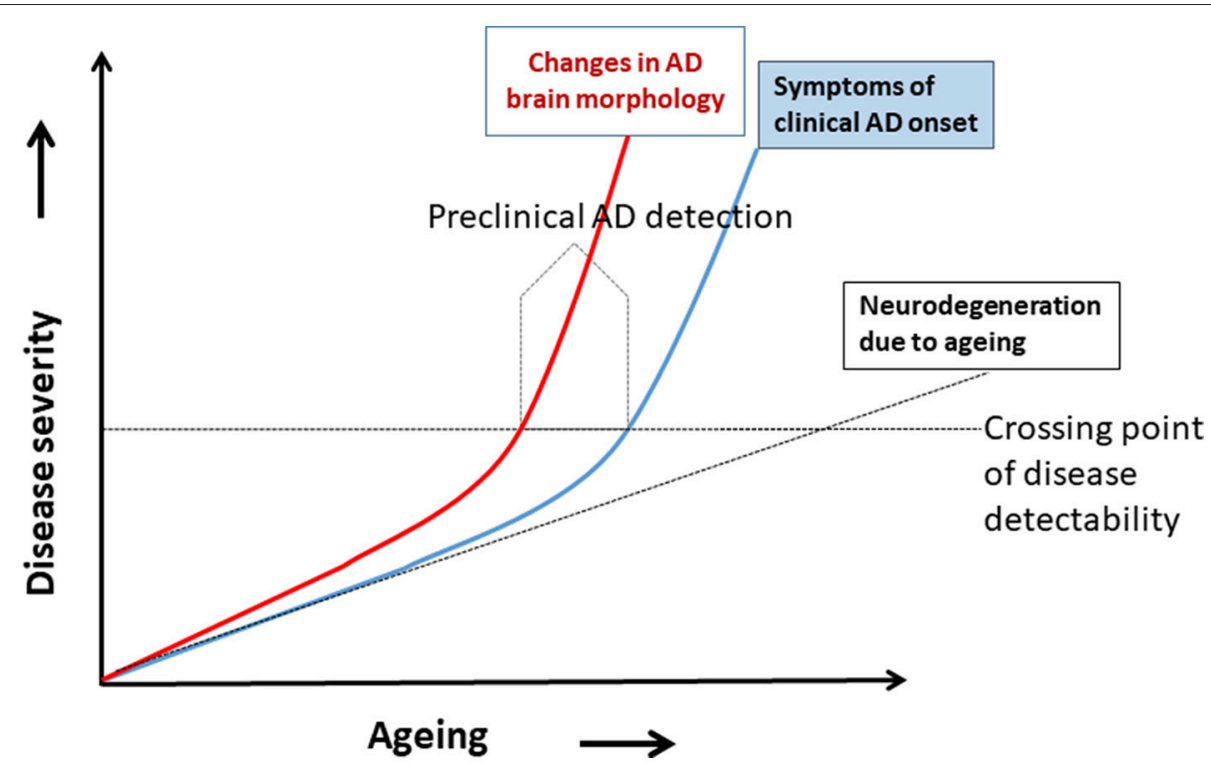

FIGURE 1 | A hypothetical model for detecting preclinical Alzheimer's disease (AD). Disease severity increases with aging, the major risk factor for an AD. Two disease trajectories represent brain morphology changes (red) and clinical AD symptoms (blue). Neurodegeneration due to aging shown by the broken black line. The model shows the hypothetical deviation of the changes in brain morphology trajectory and symptoms trajectory, and where they cross a horizontal line of disease detectability. The preclinical AD can be detected before the onset of AD symptoms (modified from Khan, 2016).

broken black line. The model shows deviations of the brain morphology trajectory and the clinical symptoms trajectory as they cross a hypothetical line of disease detectability. The trajectory of neurodegeneration due to normal aging crosses this line much later in life. Note that the changes in brain morphology increased much earlier than clinical symptoms; this indicates that the pathological changes and abnormalities in brain cell signaling (neuronal network function) occur earlier in disease progression than symptoms, such that CSF biomarkers, for example, would be detectable even in the absence of symptoms. Preclinical AD could thus be detected before the onset of $\mathrm{AD}$ symptoms (Figure 1). Preclinical diagnosis of $\mathrm{AD}$ is possible when brain morphology due to $\mathrm{AD}$ pathology started to change (box "Preclinical AD detection" in Figure 1), (subtle changes in brain white matters, minute changes in brain metabolites, and abnormalities in the neuronal network by functional MRI) and biomarkers of brain morphology changes can detect such signals. It is at this point in disease progression that advanced non-invasive neuroimaging of morphologic biomarkers with modalities, such as rs-fMRI, DTI MRI, ASL MRI, and PET, have enormous potential for diagnosis of preclinical AD.

The abnormalities in the brain due to the onset of $\mathrm{AD}$ pathology start 10-20 years before symptoms of cognitive deficiencies appear in genetically susceptible cases (Morris, 2005; Reiman et al., 2012). In one study, brain MRI was used to image brain atrophy in individuals classified as asymptomatic AD mutation carriers (presymptomatic preclinical). A recent study found that brain atrophy could be detected 1-8 years before the clinical symptoms of familial AD appeared (Kinnunen et al., 2017). A similar approach to detecting preclinical AD based on MRI-measured brain atrophy over time is not as simple for sporadic $\mathrm{AD}$, however. More research is necessary to validate the preclinical AD category of "asymptomatic at risk." Brain amyloidosis (higher $\mathrm{A} \beta$ deposition) in a cognitively normal individual has a higher likelihood of progression from preclinical stages to symptomatic stages of AD.

\section{APPLICABILITY OF CEREBROSPINAL FLUID (CSF) BIOMARKERS IN PRECLINICAL ALZHEIMER'S DISEASE DIAGNOSIS}

Widely researched CSF AD biomarkers are low $A \beta_{42}$, high tau, and high p-tau (phosphorylated tau) levels compared to age-matched non-demented controls. Three CSF biomarkers represent three different aspects of $\mathrm{AD}$ brain pathology, respectively. Low levels of $A \beta_{42}$ reflects higher amyloid plaques (amylolysis), high levels of tau represents neurodegeneration, and high p-tau level correlates with high levels of neurofibrillary tangles (NFTs) in the AD brain. As a single test CSF biomarkers are not accurate to detect conversion of MCI to $\mathrm{AD}$; however, negative CSF results in MCI cases can accurately predict conversion of non-Alzheimer's disease (Ritchie et al., 2017). Moreover, an evaluation of CSF biomarkers found them to have the ability to predict memory decline in individuals with aging (Fagan et al., 2007; Gustafson et al., 2007; Stomrud et al., 2007; Jansen et al., 2015). Therefore, CSF biomarkers can be used as part of a preclinical biomarker panel that can predict developing $\mathrm{AD}$ in the future.

CSF biomarker patterns of preclinical AD were found to be different in middle aged asymptomatic cases in a recent 
longitudinal study (Sutphen et al., 2015). Besides established AD $\mathrm{CSF},\left(\mathrm{A} \beta_{42}\right.$, tau, and $\mathrm{p}$-tau $)$ there are other CSF biomarkers that are more close to the neurodegeneration in preclinical AD stage. Such recently studied CSF biomarkers are neurofilament light chain, neurogranin, inflammatory markers, and tau fragments. Levels of CSF neurogranin are high in $\mathrm{AD}$ and progressive $\mathrm{AD}$ cases (Kester et al., 2015). Higher levels of neurogranin represent synaptic dysfunction and neurodegeneration. Neurogranin level was correlated with tau but not $\mathrm{A} \beta$, which indicates it can be a measure of neurodegeneration, not levels of $A \beta$ deposition. The levels of neurofilament light chain concentration were also high in AD progression (Zetterberg et al., 2016). Neurofilament light chain is a measure of axonal degeneration due to underlying preclinical AD. CSF inflammatory markers such as IL-15, MCP1, VEGFR-1, sICAM1, sVCAM-1, and VEGF-D were found to correlate with the levels of tau and p-tau (Popp et al., 2017). More research and validation is needed for these newly incorporated CSF biomarkers before considering them definitive preclinical AD biomarkers. Longitudinal follow-up of CSF biomarkers in individuals in risk cohort will be more effective than crosssectional cohort for determining preclinical $\mathrm{AD}$ progression.

\section{ADVANCED MRI AND PET-BASED NEUROIMAGING FOR THE DIAGNOSIS OF PRECLINICAL ALZHEIMER'S DISEASE}

Non-invasive imaging of the brain is a promising tool for the early detection of AD. The most widely researched neuroimaging biomarkers of $\mathrm{AD}$ are summarized in Table 1. Advanced neuroimaging techniques are most promising in detecting the disease at its earliest stage for initiating therapeutic intervention and finding individuals at risk of $\mathrm{AD}$. In fact, hippocampus volume is one of the first brain areas affected due to preclinical AD pathology. Advanced MRI-based neuroimaging techniques and protocols have been introduced to detect more subtle changes in brain tissues at the microscopic level (Table 2). Tissues and cell damage that precede neurodegeneration include loss of synapses, loss of axonal integrity, demyelination, loss of microtubule assembly, and minute changes in levels of brain metabolites. Resting-state functional MRI (rs-fMRI), DTI, and ASL MRI have been developed to detect these preclinical AD biomarkers and are described here. Longitudinal follow-up of imaging biomarkers in individuals in an at risk cohort will be more effective than a cross-sectional cohort for determining preclinical AD progression.

\section{Resting-State Functional MRI (rs-fMRI)}

Resting-state functional MRI was first developed by Biswal et al. (1995) to detect low-frequency fluctuations in the resting brain. In principle, it measures changes in paramagnetic properties of oxyhemoglobin/deoxy-hemoglobin in blood flowing through different brain regions influenced by changes in neuronal network activity. In the resting brain, the neuronal network is linearly dependent on spontaneous low-frequency fluctuations of the blood oxygen-dependent (BOLD) signals detected by fMRI in different brain areas. In a task-free state, functional
TABLE 1 | Neuroimaging biomarkers in Alzheimer's disease.

\begin{tabular}{ll}
\hline Neuroimaging biomarker & Biomarker readout associated with AD \\
\hline $\mathrm{MRI}^{*}$ & Atrophy \\
$\mathrm{fMRI}$ & Disrupted neural network \\
${ }^{11} \mathrm{C}^{-P I B ~ P E T}{ }^{*}$ & Increased amyloid plaque binding to PIB \\
${ }^{18} \mathrm{~F}-\mathrm{A} \beta$-binding compound-PET $^{\star *}$ & Higher amount of amyloid in brain \\
${ }^{18} \mathrm{FDG}^{-P E T^{*}}$ & Low brain metabolism measured by \\
& decreased glucose uptake
\end{tabular}

$A \beta$, amyloid beta; $A D$, Alzheimer's disease; FDG, fluoro-2-deoxy-D-glucose; $f M R l$, functional MRI; MRI, magnetic resonance imaging; PET, positron emission tomography; $P I B$, Pittsburgh compound $B$.

*Included in the NIA-2011 and IWG-2014 criteria to support diagnosis of AD for research purposes.

${ }^{* *}$ Approved by FDA and EMA.

connectivity analysis can detect subtle changes in brain network differences between individuals with the early-stage disease and healthy controls. The neuronal network and synaptic activities are beginning to change in preclinical $\mathrm{AD}$, before the symptomatic manifestation of AD. Thus, rs-fMRI enables functional connectivity analysis to detect subtle brain network abnormalities in the very beginning of $\mathrm{AD}$ pathology in the brain. Recently, lower functional connectivity measured by rs-fMRI has also been demonstrated to be an indicator of pre-MCI and predementia due to $\mathrm{AD}$ in longitudinal studies of individuals with preclinical AD (Buckley et al., 2017) (Table 2).

\section{Diffusion Tensor Imaging (DTI) With sMRI}

DTI, sometimes called diffusion-weighted imaging (DWI), was developed in the last decade of the twentieth century (Moseley et al., 1990; Beaulieu and Allen, 1994; Pierpaoli and Basser, 1996; Pierpaoli et al., 1996). In principle, it measures the probability distribution of diffusion of water molecules in the brain in terms of the diffusion tensor. In the ideal case, if there are no hindrances, the probability distribution of diffusion of water molecules should be isotropic. A brain has nerve fibers and tightly associated axonal bundles; therefore, the distribution of water molecules should be highly anisotropic in non-demented normal brains. The phenomenon of white matter loss starts at the preclinical AD stage. This loss of white matter decreases the anisotropic nature of the diffusion of the water molecules. DTI calculates two measurable quantities from the anisotropic nature of diffusion of water molecules by sMRI in the region of interest in the brain. Those two quantities are fractional anisotropy (FA) and mean diffusion coefficient (MD). Increased MD and decreased FA values indicate loss of white matter in $\mathrm{AD}$ and MCI brains indicating that MD and FA may be potential neuroimaging biomarkers of early-stage AD. Several studies have shown that DTI has the ability to distinguish between AD, MCI, and agematched control case (Chua et al., 2009; a meta-analysis of 41 DTI studies by Sexton et al., 2011) (Table 2).

Expanding on this work, DTI technology combined with novel mathematical tools has been used recently to identify preclinical $\mathrm{AD}$ cases. New evidence suggests that white matter alterations begin in preclinical $\mathrm{AD}$ and can be measured by 
TABLE 2 | Preclinical Alzheimer's disease neuroimaging biomarkers.

\begin{tabular}{|c|c|c|c|c|}
\hline Modality & Parameter & Values in preclinical AD & Notes & References \\
\hline rs-fMRI & $\begin{array}{l}\text { Paramagnetic property of } \\
\text { oxy-hemoglobin/deoxy- } \\
\text { hemoglobin in blood } \\
\text { flow }\end{array}$ & $\begin{array}{l}\text { Low-frequency } \\
\text { spontaneous fluctuation of } \\
\text { BOLD signal } \\
\text { Reduced functional } \\
\text { connectivity }\end{array}$ & $\begin{array}{l}\text { rs-fMRI can detect abnormalities before } \\
\text { brain volume loss } \\
\text { No regulatory guidelines by FDA or EMA }\end{array}$ & $\begin{array}{l}\text { Machulda et al., 2011; } \\
\text { Sheline and Raichle, } \\
\text { 2013; Buckley et al., } \\
2017\end{array}$ \\
\hline DTI with sMRI & $\begin{array}{l}\text { Diffusion of water } \\
\text { molecules in brain }\end{array}$ & $\begin{array}{l}\text { Higher overall mean } \\
\text { diffusivity of water } \\
\text { molecules } \\
\text { Lower fractional anisotropy }\end{array}$ & $\begin{array}{l}\text { Region specificity } \\
\text { Detectable abnormality in WM networks in } \\
\text { preclinical } A D \\
\text { No regulatory guidelines by FDA or EMA }\end{array}$ & $\begin{array}{l}\text { Sexton et al., 2011; } \\
\text { Racine et al., 2014; } \\
\text { Fischer et al., 2015; } \\
\text { Nedelska et al., } 2015\end{array}$ \\
\hline ASL/sMRI & $\begin{array}{l}\text { CBF traced by } \\
\text { magnetically labeled } \\
\text { water molecules }\end{array}$ & $\begin{array}{l}\text { Decreased blood flow in } \\
\text { brain }\end{array}$ & $\begin{array}{l}\text { Consistent with vascular hypothesis of AD } \\
\text { Could be useful biomarker for tracking } \\
\text { disease severity and progression } \\
\text { No radiotracer or contrast reagents } \\
\text { No regulatory guidelines by FDA or EMA }\end{array}$ & $\begin{array}{l}\text { Alsop et al., 2010; Wang } \\
\text { et al., 2013; Wierenga } \\
\text { et al., 2014; Hays et al., } \\
2016\end{array}$ \\
\hline${ }^{18} \mathrm{FDG}-\mathrm{PET}$ & $\begin{array}{l}\text { Glucose uptake in } \\
\text { different brain regions }\end{array}$ & $\begin{array}{l}\text { Glucose uptake using } \\
{ }^{18} \text { FDG }\end{array}$ & $\begin{array}{l}\text { Useful for differential diagnosis of AD and } \\
\text { FTD } \\
\text { Brain region-specific differentiation } \\
\text { capability } \\
\text { Can be used for differential diagnosis per } \\
\text { FDA or EMA }\end{array}$ & $\begin{array}{l}\text { Mosconi et al., 2006; } \\
\text { Ewers et al., 2013, } 2014\end{array}$ \\
\hline Tau- ${ }^{18}$ F-T807-PET & $\begin{array}{l}\text { Region specific } \\
\text { distribution of tau } \\
\text { deposition }\end{array}$ & ${ }^{18} \mathrm{~F}-\mathrm{T} 807$ & $\begin{array}{l}\text { Progression of } A D \text { related to } \\
\text { neurodegeneration due to tau deposition }\end{array}$ & Johnson et al., 2016 \\
\hline
\end{tabular}

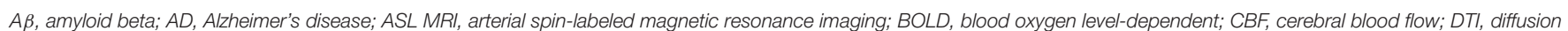

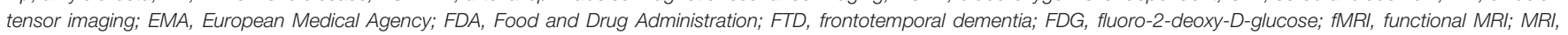

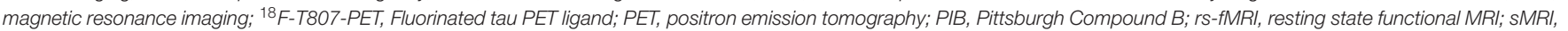
structural MRI; WM, white matter.

DTI (Racine et al., 2014; Kantarci et al., 2017). White matter primarily consists of axon and myelin sheets that is altered by $\mathrm{AD}$ pathology. Axonal degeneration and deformation of myelin sheets are early events that occur before the wide-spread neuronal loss in the AD brain. Among the neuroimaging techniques, DTI is the best suited to assess degeneration of myelinated nerve fibers in the brain. By applying tractography and graph theory in DTI, a study reported alterations within the entire white matter network in preclinical $\mathrm{AD}$, even before structural markers of significant neurodegeneration, such as atrophy by MRI and reduced cortical glucose utilization by ${ }^{18}$ FDG-PET, were detected (Fischer et al., 2015). Moreover, the alteration of DTI parameters (FA and $\mathrm{MD})$ were correlated with common risk factors of sporadic $\mathrm{AD}$ (Adluru et al., 2014).

\section{Arterial Spin Labeling (ASL) MRI}

ASL/MRI imaging of $\mathrm{AD}$ is consistent with the hypothesis of vascular abnormality of the AD. ASL was first developed in 1992 for imaging the rat brain using magnetically labeled blood water (arterial spin labeling) followed by MRI (Detre et al., 1992). The principle of ASL is based on imaging magnetically labeled blood water in brain tissues of a region of interest by applying a $180^{\circ}$ radio-frequency pulse (Detre et al., 2009, 2012). In the next step, the local changes of magnetization in brain tissue by blood flow with magnetically labeled water are measured by scanning with normal MRI sequence scanning mode. It has the ability to identify vascular factors in neurodegenerative diseases such as AD and vascular dementias (Detre et al., 2012). Cerebral blood flow $(\mathrm{CBF})$ is a possible biomarker of $\mathrm{AD}$ that can be measured by ASL MRI. Typical CBF images by ASL MRI measure reduced $\mathrm{CBF}$ in $\mathrm{AD}$, and can even differentiate between $\mathrm{MCI}$, and age-matched control groups (Wang et al., 2013). Reduced CBF values measured by ASL MRI were found to be region specific $\mathrm{AD}$ patients compared to age-matched control cases. Reduced CBF occurs in the lateral prefrontal cortex, posterior cingulate, precuneus, and inferior parietal areas of AD brains (Alsop et al., 2000, 2010; Johnson et al., 2005; Dai et al., 2009) (Table 2). CBF is easy to follow over time and imaging a biomarker can be useful to follow the disease's condition and prognosis. It has been hypothesized that abnormality in $\mathrm{CBF}$ occurs much earlier than cognitive deficits appear in $\mathrm{AD}$, possibly earlier than wide-spread brain atrophy or plaque/tangle formation. Recent studies showed that ASL MRI can be extended to detect preclinical AD, at least for research purposes (Wierenga et al., 2014; Hays et al., 2016). 


\section{AD BRAIN IMAGING BY POSITRON EMISSION TOMOGRAPHY (PET)}

\section{Amyloid Imaging by PET as AD Biomarker}

$A \beta$ deposition can be found in the neocortical area of the brain, one of the first areas affected due to preclinical $\mathrm{AD}$ pathology. Imaging of amyloid as a biomarker of $\mathrm{AD}$ is based on the popular yet controversial "amyloid cascade hypothesis" of AD (Hardy and Allsop, 1991; Hardy and Higgins, 1992). According to this oversimplified hypothesis, toxic deposition of amyloid in the $\mathrm{AD}$ brain causes synaptic loss and neuronal apoptosis; thus, measuring $\mathrm{A} \beta$ aggregates in antemortem $\mathrm{AD}$ brain imaging by $\mathrm{PET}$ would give the right $\mathrm{AD}$ diagnosis (Table 2). This hypothesis also supports the idea that amyloid plaque deposition is the primary pathophysiologic change that occurs in preclinical AD. Since fibrillary tau deposition is common in another neurodegenerative disease (Tauopathy, Frontotemporal dementia, Corticobasal degeneration), amyloid imaging by tau would have higher specificity. Klunk et al. (2004) were first to develop ${ }^{11} \mathrm{C}$-PIB (2-(4'-[11C] methylaminophenyl)6-hydroxybenzothiazole or Pittsburgh compound $\mathrm{B}$ ) as an $\mathrm{A} \beta$ PET imaging agents (Klunk et al., 2004). The ${ }^{11}$ C-PIB-PET imaging biomarker has a limitation in terms of sensitivity specificity. A study found ${ }^{11} \mathrm{C}$-PIB-PET positive in about $20-30 \%$ of cases of cognitively normal individuals (Pike et al., 2007). On the other hand, a report demonstrated that $\sim 16 \%$ of patients with probable AD were PIB PET negative (Shimada et al., 2011). As A $\beta$ plaque is not associated with dementia in $\mathrm{AD}$, the earliest event in preclinical $\mathrm{AD}$, synaptic loss, would not be expected to correlate with ${ }^{11} \mathrm{C}$-PIB-PET alone. A longitudinal study of PIB-PET found no correlation of PIB uptake depending their dementia status in age-matched control, $\mathrm{MCI}$, and $\mathrm{AD}$ individuals (Jack et al., 2009). Therefore, ${ }^{11} \mathrm{C}$-PIB-PET may provide evidence of amyloid deposit in the brain but may not be useful for diagnosing preclinical $\mathrm{AD}$ alone. Another $\mathrm{A} \beta$ PET imaging compound, ${ }^{18} \mathrm{~F}$-florbetapir demonstrated greater specificity than CSF $\mathrm{A} \beta_{42}$ (Mattsson et al., 2014). The half-life of positron-emitting ${ }^{11} \mathrm{C}$ PIB $(20.33 \mathrm{~min})$ is much lower than that of ${ }^{18} \mathrm{~F}(109.77 \mathrm{~min})$. While ${ }^{18} \mathrm{~F}$ compounds provide a shorter window for conducting an imaging study, this also means that the ${ }^{18} \mathrm{~F}$ radiotracer must be made in-house using a cyclotron, or within a range consistent with the 20-min half-life. Other well studied $A \beta$ radiotracers are ${ }^{11} \mathrm{C}-\mathrm{BF} 227$ and ${ }^{18} \mathrm{~F}-\mathrm{NAV} 4694$. A recent study found that $\mathrm{A} \beta$-PET is suitable for defining preclinical AD along with CSF biomarkers (Dubois et al., 2016). Moreover ante mortem ${ }^{11} \mathrm{C}$ PIB-PET scanning results were correlated with the Thal amyloid deposition stages (Murray et al., 2015). Amyloid plaque score in terms of Thal stage has been incorporated in NIA-AA (2011) AD neuropathological criteria (Hyman et al., 2012).

\section{Biomarker of Glucose Metabolism in AD by PET}

Dysfunctional brain glucose metabolism is another hypothesis of $\mathrm{AD}$ pathogenesis. Temporoparietal hypometabolism is one of the brain areas first affected due to preclinical AD pathology. $\left[{ }^{18} \mathrm{~F}\right]$-fluoro-2-deoxy-D-glucose $\left({ }^{18} \mathrm{FDG}\right)$ has been extensively used as the PET agent for region-specific brain imaging. ${ }^{18}$ FDGPET imaging outcomes from $\mathrm{AD}$ patients were appropriately correlated with the mini-mental score examination (MMSE) (Jagust et al., 2009). In fact, among the PET imaging techniques, ${ }^{18}$ FDG-PET is the most widely researched imaging biomarker for AD. ${ }^{18}$ FDG-PET showed consistent low signal in the parietaltemporal area and posterior cingulate cortex. In severe $\mathrm{AD}$, the frontal cortex showed lower signal; however, other brain areas unaffected by $\mathrm{AD}$ pathologies such as the cerebellum, striatum basal ganglia and the visual and sensory cortex remained unchanged. A differential low glucose metabolism detected at different brain region by ${ }^{18} \mathrm{FDG}$-PET can be used for differential $\mathrm{AD}$ and non-AD dementia diagnosis (Silverman et al., 2001; Mosconi et al., 2008). ${ }^{18}$ FDG-PET can be used for differential $\mathrm{AD}$ diagnosis vs. other non- $\mathrm{AD}$ dementia suggested by important regulatory authorities, such as FDA and EMA. In addition to that, International panels for $\mathrm{AD}$ diagnostic criteria have included ${ }^{18}$ FDG-PET as one of the AD biomarkers (Sperling et al., 2011; Dubois et al., 2014). The Centers for Medicare and Medicaid Services (CMS) have allowed the use of ${ }^{18}$ FDGPET to establish the diagnosis of dementia due to $\mathrm{AD}$ and frontotemporal dementia (FTD). ${ }^{18} \mathrm{FDG}$-PET also has potential to predict preclinical AD pathology (Ito et al., 2015).

\section{Biomarkers of tau Imaging in AD by PET}

The hyperphosphorylated paired helical filament (PHF) that forms NFTs quantified by Braak stages are better correlated with $\mathrm{AD}$ severity and neuronal atrophy than amyloid plaques (Bierer et al., 1995; Nelson et al., 2007). Both tau and phosphorylated tau (p-tau) are increased in AD pathology considered to be the measure of neuronal injury. Some studies even showed that neuronal injuries due to tau and p-tau are earlier than abnormalities in amyloidosis (Jack and Holtzman, 2013; Jack et al., 2013). CSF tau is not the same as deposition of NFTs in the $\mathrm{AD}$ brain. Moreover, the dynamic ranges of tau and $\mathrm{p}$-tau in CSF AD biomarkers are lower than $A \beta_{42}$. Therefore, tau imaging by PET as AD preclinical should have a higher implication.

Tau-PET imaging for AD was initiated with ${ }^{18}$ FDDNP (a radiofluorinated derivative of the 2-(1-[6-(dimethylamino)-2naphthyl] ethylidene) malononitrile) showing higher binding in $\mathrm{AD}$ and MCI cases (Small et al., 2006). The first human trial of tau radiotracer ${ }^{18} \mathrm{~F}$-T807 by Siemens Molecular Imaging Biomarker Research (Culver City, CA) found higher tau levels in brain areas rich in PHF and very low in white matter (Chien et al., 2013). There are several other new tau-PET tracers that have been developed based on quinolone derivatives $\left({ }^{18} \mathrm{~F}-\mathrm{THK}-523,{ }^{18} \mathrm{~F}\right.$ THK-5105, and ${ }^{18}$ F-THK-5117) (Fodero-Tavoletti et al., 2011; Harada et al., 2013; Okamura et al., 2014). Longitudinal tauPET cohorts in patients with high-risk preclinical AD provided special distribution of deposition of tau that can allow to staging in-vivo neurodegeneration according to tau levels in preclinical AD (Johnson et al., 2016). Special distribution of tau deposition by tau-PET would serve a very important role in determining preclinical $\mathrm{AD}$ cases. For example, tau-PET ligand uptake in the neocortex and increase amyloidosis with time in longitudinal studies can find underlining preclinical $A D$ pathology. Tau-PET uptake in the medial temporal lobe can 
be due to non-AD pathology preclinical FTD (frontotemporal dementia), CBD (corticobasal degeneration), PSP (progressive supranuclear palsy), or age-related tauopathy (Crary et al., 2014). Tau-PET binding in medial temporal lobe is not useful for preclinical $\mathrm{AD}$ diagnosis since it cannot differentiate control from MCI cases. Moreover, Tau-PET binding occurs in media temporal lobe even in asymptomatic elderly cases up to Braak stage 2 .

\section{APPLICABILITY OF BRAIN NEUROIMAGING MODALITIES FOR DETECTION OF BIOMARKERS IN PRECLINICAL ALZHEIMER'S DISEASE}

A comparison of the different neuroimaging modalities used to detect preclinical AD biomarkers is shown in Table 3. ${ }^{18}$ FDG-PET imaging outcome determines region-specific subtle metabolic changes in the brain. According to metabolic dysfunction hypothesis $\mathrm{AD}$, pathologic changes first occur in the metabolic pathway of a preclinical AD brain. While ${ }^{18}$ FDGPET correlates strongly with $\mathrm{AD}$ and $\mathrm{AD}$ progression, it has the potential to distinguish $\mathrm{AD}$ vs. other non- $\mathrm{AD}$ dementia, and it strongly correlates with MMSE. Therefore, ${ }^{18}$ FDG-PET has the capability to distinguish preclinical AD. There will be some disadvantages using ${ }^{18} \mathrm{FDG}$-PET for the diagnosis of preclinical $\mathrm{AD}$. The ${ }^{18} \mathrm{FDG}$-PET signal can be affected by inflammation, local ischemia, and the behavior state of the subject (Duara et al., 2010; Shipley et al., 2013). The diagnostic criteria for the preclinical AD by IWG-AA (2015) does not list either MRI or ${ }^{18}$ FDG-PET as suitable modalities for defining preclinical AD (Dubois et al., 2016). However, IWG-AA recommends ${ }^{18}$ FDGPET for tracking progress in clinical $\mathrm{AD}$ in individuals with asymptomatic preclinical AD (Dubois et al., 2016).

rs-fMRI can detect abnormalities before brain volume loss (atrophy as determined by sMRI). It can be used to detect reduced functional connectivity in the preclinical stage of $\mathrm{AD}$. However, there are no regulatory guidelines by FDA or EMA. DTI/sMRI has the potential to detect abnormalities in white matter networks in preclinical $\mathrm{AD}$. In addition, it has the capability to detect region specificity to detect a specific region affected by preclinical $\mathrm{AD}$. ASL/MRI can detect the abnormality in $\mathrm{CBF}$ in the preclinical AD. While A $\beta$-PET imaging can only be a signature of an amount of $A \beta$ levels in the preclinical $A D$ brain, it may not be used to detect the level of neurodegeneration (Table 3).

\section{RISK FACTORS IN PRECLINICAL ALZHEIMER'S DISEASE}

Preclinical AD can be classified in terms of degree of the risk factor of developing preclinical AD (except age). Such risk factors are positive amyloidosis, positive neurodegeneration, abnormalities in synaptic function by fMRI, and positive genetic $\mathrm{AD}$ risk factors. Individuals with high-risk factors should be included in a longitudinal follow-up in a cohort to find the relationship between risk factor and development of preclinical AD. A longitudinal cohort study showed CSF $\mathrm{AD}$ biomarkers $\left(\mathrm{A} \beta_{42}\right.$ and tau $)$ and $\mathrm{A} \beta$-PET can distinguish preclinical $\mathrm{AD}$ as high risk and low-risk categories (Vos et al., 2013). In future patients in a high-risk AD category and preclinical categories can be advised to change their lifestyle and food habits to delay the disease. Longitudinal changes with different risk factor in preclinical AD follow-up until cognitively impaired will allow for estimating positive and negative predictive values of the use of $\mathrm{AD}$ biomarkers in an at-risk population.

\section{NEED FOR DIAGNOSTIC GUIDELINES FOR PRECLINICAL AD}

Ample evidence shows that $\mathrm{AD}$ has long prodromal stages (preclinical $\mathrm{AD} \rightarrow \mathrm{MCI}$ due to $\mathrm{AD}$ pathology $\rightarrow \mathrm{AD}$ dementia) before the real clinical manifestation of dementia. The earlier treatment of $\mathrm{AD}$ begins in the disease course, the more effective it is at slowing the progression of the disease. Therefore, the detection of preclinical $\mathrm{AD}$ in asymptomatic individuals has become a major $\mathrm{AD}$ research focus. A simple definition of preclinical AD by the International panel (IWG-2014): No clinical symptoms of $\mathrm{AD}$ but positive $\mathrm{AD}$ biomarker values (in CSF: decreased $A \beta_{42}$, increased tau and/or p-tau in CSF; or in brain imaging: increased fibrillary amyloid on PET; Dubois et al., 2014). This simplistic definition needs more extensive diagnostic guidelines for preclinical AD. Deposition of amyloid plaques in the brain begins decades before clinical manifestation of AD, and the NIA-AA (2011) defines preclinical AD on the basis of pathological changes in the brain that occur before a demonstration of cognitive deficits. Later, IWG and NIA-AA (2015) simplified the definition of preclinical AD as the period of time between the first evidence of neuropathological lesions in the brain to the date of first clinical symptoms of AD. Now the challenge is to find validated biomarkers capable of detecting the first evidence of neuropathological lesions in the brain. Extensive research of $\mathrm{AD}$ biomarkers over the last couple decades has shown that preclinical AD is more likely to be diagnosed using multi-modal criteria. There is a need for evidence-based guidance on how to combine validated tests and imaging modalities to diagnose $\mathrm{AD}$ before the widespread synaptic loss and irreversible neuronal damage occur.

A combination of early A $\beta$-PET, ${ }^{18}$ FDG-PET, and DTI MRI and/or fMRI to detect neurodegeneration, supported by genetic tests of the mutated APP, PSEN1, PSEN2, and APOE4, may be appropriate for preclinical AD diagnosis. Positive A $\beta$-PET, low ${ }^{18} \mathrm{FDG}$-PET, and the presence of subtle neurodegeneration on MRI has been detected in familial $\mathrm{AD}$ prior to clinical symptoms. In sporadic $\mathrm{AD}$, it would be reasonable to categories individuals with APOE4, positive A $\beta$-PET, low ${ }^{18}$ FDG-PET, and subtle neurodegeneration by MRI as having a preclinical $\mathrm{AD}$. Diagnosis of preclinical $A D$ in an individual without genetic markers but with positive A $\beta$-PET, low ${ }^{18}$ FDG-PET, and subtle evidence of neurodegeneration on MRI would have to wait until subtle evidence of cognitive decline appears that is not yet equivalent to the level indicative of MCI. 
TABLE 3 | Comparison of preclinical Alzheimer's disease neuroimaging modalities.

\begin{tabular}{|c|c|c|}
\hline Neuroimaging modalities & Differences & References \\
\hline Tau- ${ }^{18}$ F-T807-PET vs. ${ }^{13}$ C-PIB-PET & Region specific distribution of tau deposition & Johnson et al., 2016 \\
\hline Tau- ${ }^{18}$ F-THK5317-PET vs. ${ }^{18}$ FDG-PET & Progression of $A D$ is better tracked by ${ }^{18} \mathrm{FDG}-\mathrm{PET}$ & Chiotis et al., 2017 \\
\hline${ }^{18}$ FDG-PET vs. DTI with sMRI & $\begin{array}{l}\text { Whole-brain white matter network properties in } \\
\text { preclinical AD can be detected by DTI with sMRI } \\
\text { before structural markers of significant } \\
\text { neurodegeneration such as atrophy (by MRI) or } \\
\text { reduced cortical glucose utilization (by }{ }^{18} \text { FDG-PET) }\end{array}$ & Fischer et al., 2015 \\
\hline${ }^{18}$ FDG-PET vs. ASL $\backslash M R I$ & $\begin{array}{l}\text { ASL MRI is not invasive } \\
{ }^{18} \text { FDG-PET is more expensive than ASL/MRI } \\
\text { ASL/MRI operation is simple }\end{array}$ & Wolk and Detre, 2012 \\
\hline
\end{tabular}



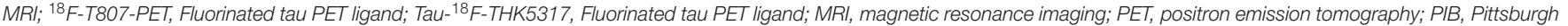
compound $B$.

\section{A POSSIBLE ALGORITHM FOR COMPREHENSIVE PRECLINICAL ALZHEIMER'S DISEASE DIAGNOSIS}

How and at what point in the lifespan can we begin to detect clear-cut signs of the ongoing neurodegenerative process of $\mathrm{AD}$ pathology that is distinct from normal aging? A multidimensional "panel" of preclinical AD biomarkers presents the best chance for a diagnosis and prediction of progression to $\mathrm{AD}$ dementia. A combination of three sets of evidence is recommended: (1) neuroimaging to detect early evidence of neurodegeneration in brain areas susceptible to $\mathrm{AD}$ pathology; (2) the genetic risk markers that predict $\mathrm{AD}$ onset; and (3) evidence of abnormalities in $\mathrm{AD}$ biomarkers (e.g., $\mathrm{CSF} A \beta_{42}$, tau, and p-tau) (Figure 2). Major exclusion criteria would not be useful for preclinical AD diagnosis. Only deposition of tau at the medial temporal lobe by tau-PET can be used as an exclusion of preclinical $\mathrm{AD}$ from other tau related preclinical non-AD dementia (preclinical FTD, CBD or agerelated tauopathy). Preclinical AD diagnostic algorithm has been proposed based on this combinatorial approach of neuroimaging, genetic testing, and CSF biomarker tests (Table 4). Incorporation of biomarkers and genetic information into the preclinical $\mathrm{AD}$ diagnostic scheme may also permit prediction of the in vivo physiological changes occurring in the brain before a clinical $\mathrm{AD}$ diagnosis.

Validation of this framework will require accurate identification of an asymptomatic cohort at risk of $\mathrm{AD}$. Longitudinal follow-up of different risk factors in preclinical AD will allow estimating accuracy, sensitivity, specificity, positive, and negative predictive values of the use of a particular $\mathrm{AD}$ biomarker at-risk population. The applicability of this diagnostic algorithm for screening of preclinical case needs extensive validation. Predicting positive and negative predictive values and false positives will depend on how preclinical $\mathrm{AD}$ cases will be selected. Standardization of operating procedure, thresholds, and cutoff values of CSF and neuroimaging biomarkers are needed to minimize between-lab and between-batch variability. Despite these challenges, the use of biomarkers holds great promise

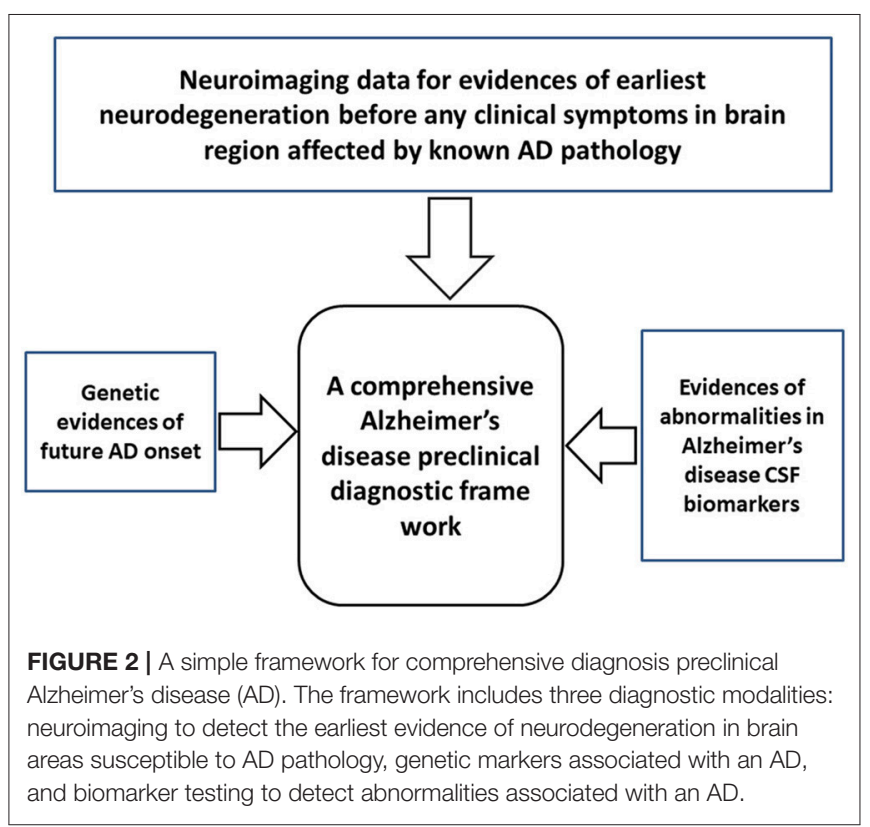

for the detection of the preclinical $\mathrm{AD}$ and the initiation of therapy at earlier stages to slow the progression of the disease. CSF sample collection is highly invasive and neuroimaging biomarkers are expensive; therefore, the ultimate goal for this research area is to find peripheral preclinical biomarkers for $\mathrm{AD}$.

\section{ISSUES CONCERNING PRECLINICAL AD BIOMARKERS}

There are several necessary issues of preclinical AD biomarkers to be addressed before application. Most important issues are diagnostic accuracy, patient selection in clinical trial, universal standardization of diagnostic protocols, cost of diagnosis, the complexity of patient selection in clinical trials, and ethical challenges. 
TABLE 4 | Algorithm for preclinical Alzheimer's disease diagnosis.

\begin{tabular}{|c|c|c|}
\hline Approach & Preclinical AD biomarkers & Preclinical AD diagnosis \\
\hline $\begin{array}{l}\text { Pre-symptomatic genetic risk } \\
\text { factors of familial } A D\end{array}$ & Familial AD genes: APP, PSEN1, PSEN2 & Definite preclinical AD \\
\hline $\begin{array}{l}\text { Combination of sporadic AD risk } \\
\text { factor genes (APOE4), CSF } \\
\text { biomarkers, and neuroimaging } \\
\text { biomarkers }\end{array}$ & $\begin{array}{l}\text { APOE4, TOMM40: Yes } \\
\text { CSF: low A } \beta_{42} \text {, high tau and p-tau } \\
\text { Neuroimaging: high A } \beta \text { by PET, neurodegeneration by low } \\
{ }^{18} \text { FDG-PET }\end{array}$ & Highly probable preclinical AD \\
\hline $\begin{array}{l}\text { Combination of sporadic AD risk } \\
\text { factor genes (APOE4), CSF } \\
\text { biomarkers, and neuroimaging } \\
\text { biomarkers }\end{array}$ & $\begin{array}{l}\text { APOE4: No } \\
\text { CSF: low } A \beta_{42} \text {, high tau and } p \text {-tau } \\
\text { Neuroimaging: high } A \beta \text { by PET, neurodegeneration by low } \\
\text { 18FDG-PET }\end{array}$ & Probable preclinical AD \\
\hline $\begin{array}{l}\text { Combination of sporadic AD risk } \\
\text { factor genes from Alzgen data } \\
\text { base, CSF biomarkers, and } \\
\text { neuroimaging biomarkers }\end{array}$ & $\begin{array}{l}\text { Susceptible gene: Alzgene database } \\
\text { CSF: low } A \beta_{42} \text {, high tau and } p \text {-tau } \\
\text { Neuroimaging: high } A \beta \text { by PET, neurodegeneration by low } \\
{ }^{18} \text { FDG-PET, deposition of tau in cortical region by }{ }^{18} \mathrm{~F}-\mathrm{T} 807-\mathrm{PET}\end{array}$ & Probable preclinical AD \\
\hline $\begin{array}{l}\text { Combination of sporadic AD risk } \\
\text { factor genes (APOE4), CSF } \\
\text { biomarkers, and neuroimaging } \\
\text { biomarkers }\end{array}$ & $\begin{array}{l}\text { APOE4: No } \\
\text { CSF: low } A \beta_{42} \text {, high tau and } p \text {-tau } \\
\text { Neuroimaging: high } A \beta \text { by PET, no neurodegeneration by } \\
{ }^{18} \text { FDG-PET, deposition of tau in cortical region by } 18 \text { F-T807-PET }\end{array}$ & Suspected preclinical AD \\
\hline $\begin{array}{l}\text { Combination of sporadic AD risk } \\
\text { factor genes (APOE4), CSF } \\
\text { biomarkers, and neuroimaging } \\
\text { biomarkers }\end{array}$ & $\begin{array}{l}\text { APOE4: No } \\
\text { CSF: no } A \beta_{42} \text {, high tau and } p \text {-tau } \\
\text { Neuroimaging: low or no } A \beta \text { by PET, neurodegeneration by low } \\
\text { 18FDG-PET }\end{array}$ & Suspected preclinical non-AD pathophysiology \\
\hline
\end{tabular}

Alzgene (http://www.alzgene.org/); A $\beta$, amyloid beta; APOE, apolipoprotein; CSF, cerebrospinal fluid; FDG, fluoro-2-deoxy-D-glucose; ${ }^{18}$ F-T807-PET, Fluorinated tau PET ligand; PET, positron emission tomography; TOMM40, translocate of outer mitochondrial membrane 40.

\section{Diagnostic Accuracy and Patient Selection}

Improved diagnostic accuracy (sensitivity, specificity, positive predictive value, negative predictive value) and universally accepted unified standard operating procedures (SOP; for sample collection, cut-off values, analysis) are urgently required. The diagnostic sensitivity (SN), specificity (SP), positive likely-hood ratio $(\mathrm{LR}+)$, and negative likely-hood ratio (LR-) of all three core CSF biomarkers $\left(\mathrm{A} \beta_{42}: \mathrm{SN}=79 \%, \mathrm{SP}=63 \%, \mathrm{LR}+=2\right.$, and $\mathrm{LR}-=0.3$; tau: $\mathrm{SN}=76 \%$, SP $=58 \%, \mathrm{LR}+=2$, and $\mathrm{LR}-$ $=0.4 ;$ p-tau: $\mathrm{SN}=78 \%, \mathrm{SP}=56 \%, \mathrm{LR}+=2$, and LR- $=$ 0.4; combination of three: $\mathrm{A} \beta_{42}: \mathrm{SN}=84 \%, \mathrm{SP}=63 \%$, LR+ $=2$, and $\mathrm{LR}-=0.3$ ) for MCI conversion to $\mathrm{AD}$ were found to be moderate by a systemic meta-analysis (Ferreira et al., 2014). The diagnostic sensitivity, specificity, positive likely-hood ratio, and negative likely-hood ratio of ${ }^{18}$ F-labeled $A \beta$-PET imaging biomarkers (Florbetapir: $\mathrm{SN}=89.6 \%, \mathrm{SP}=87.2 \%, \mathrm{LR}+=$ 7.9 and LR- $=0.108$; Florbetaben: $\mathrm{SN}=89.3 \%$, SP $=87.6 \%$, $\mathrm{LR}+=6.06$ and $\mathrm{LR}-=0.141$ ) for distinguishing $\mathrm{AD}$ with non-demented control were found to be considerably higher by a systemic meta-analysis (Yeo et al., 2015). The progression of $\mathrm{AD}$ in non-demented elderly individuals was predicted with considerable accuracy ( $\mathrm{SN}=82 \%$ and $\mathrm{SP}=93 \%$ ) by studying brain metabolic states by FDG-PET (Ewers et al., 2014). ${ }^{11}$ C-PIB-PET has higher SN (96\%), low SP (58\%), moderate LR+ (2.3), and LR- (0.07) for the conversion of MCI-AD (Zhang et al., 2014).

One of the main issues of concern of using this proposed algorithm is how to select potential patients to be screened. The selection of patients should be conducted as described in Table 4 .

\section{Universal Standardization Diagnostic Protocols}

Standard methods of sample collection, reference standards, universal cut-off values for diagnostic tests, and standard operating procedures (SOP) are urgently needed for most advanced $\mathrm{AD}$ biomarkers (CSF core biomarkers, $\mathrm{A} \beta$-PET, FDGPET, and tau-PET). A significant amount of work has been done by an IWG for a universal standardization of AD diagnostic biomarkers (Mattsson and Zetterberg, 2012; Mattsson et al., 2012, 2013; https://aibl.csiro.au/wp-content/uploads/2014/01/sperling. pdf).

\section{Estimated Costs of AD Diagnosis Tests}

No doubt, there will be several thousand dollar cost for selecting each patient, and more cost would be during longitudinal follow up. An estimated cost of MRI $(\$ 1,694-\$ 3,624)$ is higher than CSF biomarkers (http://www.comparemricost.com/. Study of 10 cities in the USA show that (Orlando, FL Dallas, TXMRI Testing Facility A MRI and Dallas, TX-MRI Testing Facility B, San Diego, CA, Salt Lake City, UT, Detroit, MI, New York, NY-MRI Testing Facility A, New York, NY-MRI Testing Facility B, Raleigh, NC, Omaha, NE) fMRI costs are even higher than MRI. Specialized bio-informatics personals with expensive equipment are the main reason for the higher cost of modern neuroimaging AD biomarkers. Moderately invasive PET imaging costs \$825-\$6,800 (http://www.newchoicehealth.com/ procedures/pet-scan-brain: National PET Scan Brain Procedure Pricing Summary). Highly invasive CSF biomarker tests are moderately expensive $(\sim \$ 40-\$ 1,000$ per test) (Fiandaca et al., 
2014; Valcárcel-Nazco et al., 2014), because highly skilled personals are required in specialized medical centers for CSF sample collection (lumbar puncture), three ELISA kits are necessary for $\left(A \beta_{42}\right.$, tau, and p-tau), and the cost of CSF biomarker tests are much higher than blood-based diagnostic tests. Neuroimaging biomarkers are expensive because modality is a technical sophistication that needs technically trained expert teams of neuroscientists, radiologists, and bioinformatics specialists. A panel of a combination of CSF and neuroimaging biomarkers would increase the predicting power of preclinical $\mathrm{AD}$ diagnosis. However, the cost of diagnosis of such $\mathrm{AD}$ biomarkers will be much higher. Peripheral AD diagnosis in preclinical $\mathrm{AD}$ phase is the best way to decrease this enormous cost.

\section{The Complexity of Patient Selection for Preclinical AD Clinical Trials}

A homogeneous set of patients with preclinical AD certainly would not be available by its own characteristic feature of heterogeneity. Therefore, several subgroups of patients with preclinical $\mathrm{AD}$ can be separated according to their initial baseline preclinical $\mathrm{AD}$ biomarker values and follow longitudinally for a longer time (5-10 years). Such sub-groups are A. genetic sub-group: Asymptomatic high genetic risk with APOE4 and TOMM40 alleles, B. Neurodegeneration subgroup: Asymptomatic neurodegeneration by brain hypometabolism/tau deposition/atrophy, and C. Asymptomatic high-risk $\mathrm{A} \beta$ deposition by $A \beta$-PET and low CSF $A \beta_{42}$ values. Because of longtime follow-up, preclinical $\mathrm{AD}$ longitudinal clinical trials should be expensive. Other drawbacks of such clinical trial are patient withdrawal, interference of comorbidity, and lifestyle changes of patients during the longitudinal long follow-up.

\section{Ethical Challenges}

Ethical issues to a conclusion and disclosure of a preclinical AD is very complex. The main ethical concerns for an individual are emotional, social, and economical. Emotional issues are feelings, fears, impact on personal motivation, and behavior to family members. A Metlife Foundation survey in 2011 found Americans middle aged and older ( $\geq 55$ years) are afraid of $\mathrm{AD}(31 \%)$, more than diabetes, heart disease, or stroke and less than cancer (41\%) (Metlife Foundation, 2011). Preclinical AD disclosure may induce anxiety and depression. Social issues, such as the social stigma of future development of $\mathrm{AD}$ and withdrawal from social events, are an impact on friendship networks. The economic impact will be enormous to an individual with a preclinical $\mathrm{AD}$ diagnosis. Health insurance companies may increase the insurance premium. An individual working in higher cognitive performing jobs, such as pilot, clinical practitioners, and nurses need to be reported to a higher authority. Regulatory authorities should develop suitable guidelines for ethical issues for informing individuals about preclinical AD diagnosis.

Keeping all of these issues in mind, one can look at the positive aspect of the disclosure of preclinical AD. More than $90 \%$ responded in a survey that they wanted to adopt a healthier lifestyle if they knew they were at risk of AD (Caselli et al., 2014). Individuals who want to take a positive outlook of preclinical AD diagnosis should be influenced to increase social contact, healthy food, and mental exercises such as numerical problem solving, meditation, and yoga.

\section{Feasibility and Utility of the Preclinical AD Diagnostic Algorithm}

The main challenge remains how to choose individuals for preclinical $\mathrm{AD}$ diagnostic clinical trials. We proposed four different categories of probable preclinical $\mathrm{AD}$ cases and definitive preclinical AD category of pre-symptomatic genetic risk factors (Table 4) to be longitudinally tested in clinical trials by proposed preclinical AD biomarkers. In longitudinal followup trials will produce four different categories of biomarkers results (amyloid + and neurodegenerative + , amyloid + and neurodegenerative-, amyloid-and neurodegenerative + , amyloidand neurodegenerative- (Pereira et al., 2017), and cognitive impairment due to $\mathrm{AD}$. Those results will be complied in a comprehensive $\mathrm{AD}$ preclinical diagnostic framework presented in Figure 2 to generate correlation of $\mathrm{AD}$ converters and $\mathrm{AD}$ non-converters with preclinical AD biomarkers.

Although challenges of cost, positive predictive values, and ethical issues are substantial this algorithm will provide a frame work of preclinical $\mathrm{AD}$ diagnosis, like lipid profiling for an individual in risk of heart disease. In the future individual with a risk of a preclinical $\mathrm{AD}$ from this framework should have suggestion from doctors to follow a healthy lifestyle.

\section{AUTHOR CONTRIBUTIONS}

The author confirms being the sole contributor of this work and approved it for publication.

\section{ACKNOWLEDGMENTS}

Financial assistance from the Intramural Research Program of the Blanchette Rockefeller Neurosciences Institute at West Virginia University, Morgantown, WV (TK), is gratefully acknowledged. The author is indebted to Ms. Cassandra George for assisting in the preparation of this manuscript. The author is grateful to the honorable editor and reviewers for their valuable comments for the improvement of this article.

\section{REFERENCES}

Adluru, N., Destiche, D. J., Lu, S. Y., Doran, S. T., Birdsill, A. C., Melah, K. E., et al. (2014). White matter microstructure in late middle-age: effects of apolipoprotein E4 and parental family history of Alzheimer's

disease. Neuroimage Clin. 4, 730-742. doi: 10.1016/j.nicl.2014.0 4.008

Alsop, D. C., Dai, W., Grossman, M., and Detre, J. A. (2010). Arterial spin labeling blood flow MRI: its role in the early characterization of Alzheimer's disease. J. Alzheimers Dis. 20, 871-880. doi: 10.3233/JAD-2010-091699 
Alsop, D. C., Detre, J. A., and Grossman, M. (2000). Assessment of cerebral blood flow in Alzheimer's disease by spinlabeled magnetic resonance imaging. Ann. Neurol. 47, 93-100. doi: 10.1002/1531-8249(200001)47:1 <93::AID-ANA15>3.0.CO;2-8

Beaulieu, C., and Allen, P. S. (1994). Determinants of anisotropic water diffusion in nerves. Magn. Reson. Med. 31, 394-400. doi: 10.1002/mrm.1910310408

Bierer, L. M., Hof, P. R., Purohit, D. P., Carlin, L., Schmeidler, J., Davis, K. L., et al. (1995). Neocortical neurofibrillary tangles correlate with dementia severity in Alzheimer's disease. Arch. Neurol. 52, 81-88. doi: 10.1001/archneur.1995.00540250089017

Biswal, B., Yetkin, F. Z., Haughton, V. M., and Hyde, J. S. (1995). Functional connectivity in the motor cortex of resting human brain using echo-planar MRI. Magn. Reson. Med. 34, 537-541. doi: 10.1002/mrm.1910340409

Buckley, R. F., Schultz, A. P., Hedden, T., Papp, K. V., Hanseeuw, B. J., Marshall, G., et al. (2017). Functional network integrity presages cognitive decline in preclinical Alzheimer disease. Neurology 89, 29-37. doi: 10.1212/WNL.0000000000004059

Caselli, R. J., Langbaum, J., Marchant, G. E., Lindor, R. A., Hunt, K. S., Henslin, B. R., et al. (2014). Public perceptions of presymptomatic testing for Alzheimer disease. Mayo Clin. Proc. 89, 1389-1396. doi: 10.1016/j.mayocp.2014.05.016

Chien, D. T., Bahri, S., Szardenings, A. K., Walsh, J. C., Mu, F., Su, M. Y., et al. (2013). Early clinical PET imaging results with the novel PHF-tau radioligand [F-18]-T807. J. Alzheimers Dis. 34, 457-468. doi: 10.3233/JAD-122059

Chiotis, K., Saint-Aubert, L., Rodriguez-Vieitez, E., Leuzy, A., Almkvist, O., Savitcheva, I., et al. (2017). Longitudinal changes of tau PET imaging in relation to hypometabolism in prodromal and Alzheimer's disease dementia. Mol. Psychiatry. doi: 10.1038/mp.2017.108. [Epub ahead of print].

Chua, T. C., Wen, W., Chen, X., Kochan, N., Slavin, M. J., Trollor, J. N., et al. (2009). Diffusion tensor imaging of the posterior cingulate is a useful biomarker of mild cognitive impairment. Am. J. Geriatr. Psychiatry 17, 602-613. doi: 10.1097/JGP.0b013e3181a76e0b

Crary, J. F., Trojanowski, J. Q., Schneider, J. A., Abisambra, J. F., Abner, E. L., Alafuzoff, I., et al. (2014). Primary age-related tauopathy (PART): a common pathology associated with human aging. Acta Neuropathol. 128, 755-766. doi: 10.1007/s00401-014-1349-0

Dai, W., Lopez, O. L., Carmichael, O. T., Becker, J. T., Kuller, L. H., and Gach, H. M. (2009). Mild cognitive impairment and Alzheimer disease: patterns of altered cerebral blood flow at MR imaging. Radiology 250, 856-866. doi: 10.1148/radiol.2503080751

Detre, J. A., Leigh, J. S., Williams, D. S., and Koretsky, A. P. (1992). Perfusion imaging. Magn. Reson. Med. 23, 37-45. doi: 10.1002/mrm.1910230106

Detre, J. A., Rao, H., Wang, D. J., Chen, Y. F., and Wang, Z. (2012). Applications of arterial spin labeled MRI in the brain. J. Magn. Reson. Imaging 35, 1026-1037. doi: $10.1002 /$ jmri.23581

Detre, J. A., Wang, J., Wang, Z., and Rao, H. (2009). Arterial spin-labeled perfusion MRI in basic and clinical neuroscience. Curr. Opin. Neurol. 22, 348-355. doi: 10.1097/WCO.0b013e32832d9505

Duara, R., Loewenstein, D. A., Greig-Custo, M. T., Raj, A., Barker, W., Potter, E., et al. (2010). Diagnosis and staging of mild cognitive impairment, using a modification of the clinical dementia rating scale: the mCDR. Int. J. Geriatr. Psychiatry 25, 282-289. doi: 10.1002/gps.2334

Dubois, B., Feldman, H. H., Jacova, C., Hampel, H., Molinuevo, J. L., Blennow, K., et al. (2014). Advancing research diagnostic criteria for Alzheimer's disease: the IWG-2 criteria. Lancet Neurol. 13, 614-629. doi: 10.1016/S1474-4422(14)70090-0

Dubois, B., Hampel, H., Feldman, H. H., Scheltens, P., Aisen, P., Andrieu, S., et al. (2016). Preclinical Alzheimer's disease: definition, natural history, and diagnostic criteria. Alzheimers Dement. 12, 292-323. doi: 10.1016/j.jalz.2016.02.002

Ewers, M., Brendel, M., Rizk-Jackson, A., Rominger, A., Bartenstein, P., Schuff, N., et al. (2014). Reduced FDG-PET brain metabolism and executive function predict clinical progression in elderly healthy subjects. Neuroimage Clin. 4, 45-52. doi: 10.1016/j.nicl.2013.10.018

Ewers, M., Insel, P. S., Stern, Y., and Weiner, M. W. (2013). Cognitive reserve associated with FDG-PET in preclinical Alzheimer disease. Neurology 80, 1194-1201. doi: 10.1212/WNL.0b013e31828970c2

Fagan, A. M., Roe, C. M., Xiong, C., Mintun, M. A., Morris, J. C., and Holtzman, D. M. (2007). Cerebrospinal fluid tau/beta-amyloid (42) ratio as a prediction of cognitive decline in nondemented older adults. Arch. Neurol. 64, 343-349. doi: 10.1001/archneur.64.3.noc60123

Ferreira, D., Perestelo-Pérez, L., Westman, E., Wahlund, L. O., Sarría, A., and Serrano-Aguilar, P. (2014). Meta-review of CSF core biomarkers in Alzheimer's disease: the state-of-the-art after the new revised diagnostic criteria. Front. Aging Neurosci. 6:47. doi: 10.3389/fnagi.2014.00047

Fiandaca, M. S., Mapstone, M. E., Cheema, A. K., and Federoff, H. J. (2014). The critical need for defining preclinical biomarkers in Alzheimer's disease. Alzheimers Dement. 10(Suppl. 3), S196-S212. doi: 10.1016/j.jalz.2014.04.015

Fischer, F. U., Wolf, D., Scheurich, A., and Fellgiebel, A. (2015). Altered wholebrain white matter networks in preclinical Alzheimer's disease. Neuroimage Clin. 8, 660-666. doi: 10.1016/j.nicl.2015.06.007

Fodero-Tavoletti, M. T., Okamura, N., Furumoto, S., Mulligan, R. S., Connor, A. R., McLean, C. A., et al. (2011). 18F-THK523: a novel in vivo tau imaging ligand for Alzheimer's disease. Brain 134, 1089-1100. doi: 10.1093/brain/awr038

Fox, N. C., Warrington, E. K., and Rossor, M. N. (1999). Serial magnetic resonance imaging of cerebral atrophy in preclinical Alzheimer's disease. Lancet 353, 2125-2125. doi: 10.1016/S0140-6736(99)00496-1

Frölich, L., Peters, O., Lewczuk, P., Gruber, O., Teipel, S. J., Gertz, H. J., et al. (2017). Incremental value of biomarker combinations to predict progression of mild cognitive impairment to Alzheimer's dementia. Alzheimers Res. Ther. 9:84. doi: 10.1186/s13195-017-0301-7

Grand, J. H., Caspar, S., and Macdonald, S. W. (2011). Clinical features and multidisciplinary approaches to dementia care. J. Multidiscip. Healthc. 4, 125-147. doi: 10.2147/JMDH.S17773

Gustafson, D. R., Skoog, I., Rosengren, L., Zetterberg, H., and Blennow, K. (2007). Cerebrospinal fluid beta-amyloid 1-42 concentration may predict cognitive decline in older women. J. Neurol. Neurosurg. Psychiatr. 78, 461-464. doi: 10.1136/jnnp.2006.100529

Harada, R., Okamura, N., Furumoto, S., Tago, T., Maruyama, M., Higuchi, M., et al. (2013). Comparison of the binding characteristics of [18F]THK-523 and other amyloid imaging tracers to Alzheimer's disease pathology. Eur. J. Nucl. Med. Mol. Imaging 40, 125-132. doi: 10.1007/s00259-012-2261-2

Hardy, J. A., and Higgins, G. A. (1992). Alzheimer's disease: the amyloid cascade hypothesis. Science 256, 184-185. doi: 10.1126/science.1566067

Hardy, J., and Allsop, D. (1991). Amyloid deposition as the central event in the aetiology of Alzheimer's disease. Trends Pharmacol. Sci. 12, 383-388. doi: 10.1016/0165-6147(91)90609-V

Hays, C. C., Zlatar, Z. Z., and Wierenga, C. E. (2016). The utility of cerebral blood flow as a biomarker of preclinical Alzheimer's disease. Cell. Mol. Neurobiol. 36, 167-179. doi: 10.1007/s10571-015-0261-z

Hubbard, B. M., Fenton, G. W., and Anderson, J. M. (1990). A quantitative histological study of early clinical and preclinical Alzheimer's disease. Neuropathol. Appl. Neurobiol. 16, 111-121.

Hyman, B. T., Phelps, C. H., Beach, T. G., Bigio, E. H., Cairns, N. J., Carrillo, M. C., et al. (2012). National Institute on Aging-Alzheimer's Association guidelines for the neuropathologic assessment of Alzheimer's disease. Alzheimers Dement. 8, 1-13. doi: 10.1016/j.jalz.2011.10.007

Ito, K., Fukuyama, H., Senda, M., Ishii, K., Maeda, K., Yamamoto, Y., et al. (2015). Prediction of outcomes in mild cognitive impairment by using 18F-FDG-PET: a multicenter study. J. Alzheimers Dis. 45, 543-552. doi: 10.3233/JAD-141338

Jack, C. R. Jr, and Holtzman, D. M. (2013). Biomarker modeling of Alzheimer's disease. Neuron 80, 1347-1358. doi: 10.1016/j.neuron.2013.12.003

Jack, C. R. Jr, Knopman, D. S., Jagust, W. J., Shaw, L. M., Aisen, P. S., Weiner, M. W., et al. (2010). Hypothetical model of dynamic biomarkers of the Alzheimer's pathological cascade. Lancet Neurol. 9, 119-128. doi: 10.1016/S1474-4422(09)70299-6

Jack, C. R. Jr, Lowe, V. J., Weigand, S. D., Wiste, H. J., Senjem, M. L., Knopman, D. S., et al. (2009). Serial PIB and MRI in normal, mild cognitive impairment and Alzheimer's disease: implications for sequence of pathological events in Alzheimer's disease. Brain 132, 1355-1365. doi: 10.1093/brain/awp062

Jack, C. R. Jr., Wiste, H. J., Weigand, S. D., Knopman, D. S., Lowe, V., Vemuri, P., et al. (2013). Amyloid-first and neurodegeneration-first profiles characterize incident amyloid PET positivity. Neurology 81, 1732-1740. doi: 10.1212/01.wnl.0000435556.21319.e4

Jagust, W. J., Landau, S. M., Shaw, L. M., Trojanowski, J. Q., Koeppe, R. A., Reiman, E. M., et al. (2009). Relationships between biomarkers in aging and dementia. Neurology 73, 1193-1199. doi: 10.1212/WNL.0b013e3181bc010c 
Jansen, W. J., Ossenkoppele, R., Knol, D. L., Tijms, B. M., Scheltens, P., Verhey, F. R., et al. (2015). Prevalence of cerebral amyloid pathology in persons without dementia: a meta-analysis. JAMA 313, 1924-1938. doi: 10.1001/jama.2015.4668

Johnson, K. A., Fox, N. C., Sperling, R. A., and Klunk, W. E. (2012). Brain imaging in Alzheimer disease. Cold Spring Harb. Perspect. Med. 2:a006213. doi: 10.1101/cshperspect.a006213

Johnson, K. A., Schultz, A., Betensky, R. A., Becker, J. A., Sepulcre, J., Rentz, D., et al. (2016). Tau positron emission tomographic imaging in aging and early Alzheimer disease. Ann. Neurol. 79, 110-119. doi: 10.1002/ana.24546

Johnson, N. A., Jahng, G. H., Weiner, M. W., Miller, B. L., Chui, H. C., Jagust, W. J., et al. (2005). Pattern of cerebral hypoperfusion in Alzheimer disease and mild cognitive impairment measured with arterial spin-labeling MR imaging: initial experience. Radiology 234, 851-859. doi: 10.1148/radiol.23430 40197

Kantarci, K., Murray, M. E., Schwarz, C. G., Reid, R. I., Przybelski, S. A., Lesnick, T., et al. (2017). White-matter integrity on DTI and the pathologic staging of Alzheimer's disease. Neurobiol. Aging 56, 172-179. doi: 10.1016/j.neurobiolaging.2017.04.024

Kester, M. I., Teunissen, C. E., Crimmins, D. L., Herries, E. M., Ladenson, J. H., Scheltens, P., et al. (2015). Neurogranin as a cerebrospinal fluid biomarker for synaptic loss in symptomatic Alzheimer disease. JAMA Neurol. 72, 1275-1280. doi: 10.1001/jamaneurol.2015.1867

Khan, T. K. (2016). Biomarkers in Alzheimer's Disease. London: Academic Press, 37.

Kinnunen, K. M., Cash, D. M., Poole, T., Frost, C., Benzinger, T. L. S., Ahsan, R. L., et al. (2017). Presymptomatic atrophy in autosomal dominant Alzheimer's disease: a serial MRI study. Alzheimers Dement. 14, 43-53. doi: $10.1016 /$ j.jalz.2017.06.2268

Klunk, W. E., Engler, H., Nordberg, A., Wang, Y., Blomqvist, G., Holt, D. P., et al. (2004). Imaging brain amyloid in Alzheimer's disease with Pittsburgh Compound-B. Ann. Neurol. 55, 306-319. doi: 10.1002/ana.20009

Machulda, M. M., Jones, D. T., Vemuri, P., McDade, E., Avula, R., Przybelski, S., et al. (2011). Effect of APOE epsilon4 status on intrinsic network connectivity in cognitively normal elderly subjects. Arch. Neurol. 68, 1131-1136. doi: 10.1001/archneurol.2011.108

Mattsson, N., and Zetterberg, H. (2012). What is a certified reference material. Biomark. Med. 6, 369-370. doi: 10.2217/bmm.12.37

Mattsson, N., Andreasson, U., Persson, S., Carrillo, M. C., Collins, S., Chalbot, S., et al. (2013). CSF biomarker variability in the Alzheimer's Association quality control program. Alzheimers Dement. 9, 251-261. doi: 10.1016/j.jalz.2013.01.010

Mattsson, N., Insel, P. S., Landau, S., Jagust, W., Donohue, M., Shaw, L. M., et al. (2014). Diagnostic accuracy of CSF A $\beta 42$ and florbetapir PET for Alzheimer's disease. Ann. Clin. Transl. Neurol. 1, 534-543. doi: 10.1002/acn3.81

Mattsson, N., Zegers, I., Andreasson, U., Bjerke, M., Blankenstein, M. A., Bowser, R., et al. (2012). Reference measurement procedures for Alzheimer's disease cerebrospinal fluid biomarkers: definitions and approaches with focus on amyloid B42. Biomark. Med. 6, 409-417. doi: 10.2217/bmm.12.39

McKhann, G. M., Knopman, D. S., Chertkow, H., Hyman, B. T., Jack, C. R. Jr, Kawas, C. H., et al. (2011). The diagnosis of dementia due to Alzheimer's disease: recommendations from the National Institute on Aging-Alzheimer's Association workgroups on diagnostic guidelines for Alzheimer's disease. Alzheimers Dement. 7, 263-269. doi: 10.1016/j.jalz.2011.03.005

Metlife Foundation (2011). What America Thinks: MetLife Foundation Alzheimer's Survey. New York, NY: Harris Interactive.

Mintun, M. A., Larossa, G. N., Sheline, Y. I., Dence, C. S., Lee, S. Y., Mach, R. H., et al. (2006). [11C]PIB in a nondemented population: potential antecedent marker of Alzheimer disease. Neurology 67, 446-452. doi: 10.1212/01.wnl.0000228230.26044.a4

Morris, J. C. (2005). Early-stage and preclinical Alzheimer's disease. Alzheimer Dis. Assoc. Disord. 19, 163-165. doi: 10.1097/01.wad.0000184005.22611.cc

Mosconi, L., Sorbi, S., de Leon, M. J., Li, Y., Nacmias, B., Myoung, P. S., et al. (2006). Hypometabolism exceeds atrophy in presymptomatic early-onset familial Alzheimer's disease. J. Nucl. Med. 47, 1778-1786.

Mosconi, L., Tsui, W. H., Herholz, K., Pupi, A., Drzezga, A., Lucignani, G., et al. (2008). Multicenter standardized 18F-FDG PET diagnosis of mild cognitive impairment, Alzheimer's disease, and other dementias. J. Nucl. Med. 49, 390-398. doi: 10.2967/jnumed.107.045385
Moseley, M. E., Cohen, Y., Kucharczyk, J., Mintorovitch, J., Asgari, H. S. Wendland, M. F., et al. (1990). Diffusion-weighted MR imaging of anisotropic water diffusion in cat central nervous system. Radiology 176, 439-445. doi: 10.1148/radiology.176.2.2367658

Murray, M. E., Lowe, V. J., Graff-Radford, N. R., Liesinger, A. M., Cannon, A., Przybelski, S. A., et al. (2015). Clinicopathologic and 11C-Pittsburgh compound B implications of Thal amyloid phase across the Alzheimer's disease spectrum. Brain 138, 1370-1381. doi: 10.1093/brain/awv050

Nedelska, Z., Schwarz, C. G., Boeve, B. F., Lowe, V. J., Reid, R. I., Przybelski, S. A., et al. (2015). White matter integrity in dementia with Lewy bodies: a voxelbased analysis of diffusion tensor imaging. Neurobiol. Aging 36, 2010-2017. doi: 10.1016/j.neurobiolaging.2015.03.007

Nelson, P. T., Jicha, G. A., Schmitt, F. A., Liu, H., Davis, D. G., Mendiondo, M. S., et al. (2007). Clinicopathologic correlations in a large Alzheimer disease center autopsy cohort: neuritic plaques and neurofibrillary tangles "do count" when staging disease severity. J. Neuropathol. Exp. Neurol. 66, 1136-1146. doi: 10.1097/nen.0b013e31815c5efb

Okamura, N., Furumoto, S., Fodero-Tavoletti, M. T., Mulligan, R. S., Harada, R., Yates, P., et al. (2014). Non-invasive assessment of Alzheimer's disease neurofibrillary pathology using 18F-THK5105 PET. Brain 137, 1762-1771. doi: 10.1093/brain/awu064

Pereira, J. B., van Westen, D., Stomrud, E., Strandberg, T. O., Volpe, G., Westman, E., et al. (2017). Abnormal structural brain connectome in individuals with preclinical Alzheimer's disease. Cereb. Cortex. doi: 10.1093/cercor/bhx236. [Epub ahead of print].

Petersen, R. C., Doody, R., Kurz, A., Mohs, R. C., Morris, J. C., Rabins, P. V., et al. (2001). Current concepts in mild cognitive impairment. Arch. Neurol. 58, 1985-1992. doi: 10.1001/archneur.58.12.1985

Petersen, R. C., Smith, G. E., Waring, S. C., Ivnik, R. J., Tangalos, E. G., and Kokmen, E. (1999). Mild cognitive impairment: clinical characterization and outcome. Arch. Neurol. 56, 303-308. doi: 10.1001/archneur. 56.3.303

Pierpaoli, C., and Basser, P. J. (1996). Toward a quantitative assessment of diffusion anisotropy. Magn. Reson. Med. 36, 893-906. doi: 10.1002/mrm.1910360612

Pierpaoli, C., Jezzard, P., Basser, P. J., Barnett, A., and Di Chiro, G. (1996). Diffusion tensor MR imaging of human brain. Radiology 201, 637-648. doi: 10.1148/radiology.201.3.8939209

Pike, K. E., Savage, G., Villemagne, V. L., Ng, S., Moss, S. A., Maruff, P., et al. (2007). $\beta$-amyloid imaging and memory in non-demented individuals: evidence for preclinical Alzheimer's disease. Brain 130, 2837-2844. doi: 10.1093/brain/awm238

Popp, J., Oikonomidi, A., Tautvydaite, D., Dayon, L., Bacher, M., Migliavacca, E., et al. (2017). Markers of neuroinflammation associated with Alzheimer's disease pathology in older adults. Brain Behav. Immun. 62, 203-211. doi: 10.1016/j.bbi.2017.01.020

Racine, A. M., Adluru, N., Alexander, A. L., Christian, B. T., Okonkwo, O. C., Oh, J., et al. (2014). Associations between white matter microstructure and amyloid burden in preclinical Alzheimer's disease: a multimodal imaging investigation. Neuroimage Clin. 4, 604-614. doi: 10.1016/j.nicl.2014. 02.001

Reiman, E. M., Quiroz, Y. T., Fleisher, A. S., Chen, K., Velez-Pardo, C., JimenezDel-Rio, M., et al. (2012). Brain imaging and fluid biomarker analysis in young adults at genetic risk for autosomal dominant Alzheimer's disease in the presenilin 1 E280A kindred: a case-control study. Lancet Neurol. 11, 1048-1056. doi: 10.1016/S1474-4422(12)70228-4

Ritchie, C., Smailagic, N., Noel-Storr, A. H., Ukoumunne, O., Ladds, E. C., and Martin, S. (2017). CSF tau and the CSF tau/ABeta ratio for the diagnosis of Alzheimer's disease dementia and other dementias in people with mild cognitive impairment (MCI). Cochrane Database Syst. Rev. 3:CD010803. doi: 10.1002/14651858.CD010803.pub2

Scheinin, N. M., Aalto, S., Koikkalainen, J., Lötjönen, J., Karrasch, M., Kemppainen, N., et al. (2009). Follow-up of [11C] PIB uptake and brain volume in patients with Alzheimer disease and controls. Neurology 73, 1186-1192. doi: 10.1212/WNL.0b013e3181bacf1b

Sexton, C. E., Kalu, U. G., Filippini, N., Mackay, C. E., and Ebmeier, K. P. (2011). A meta-analysis of diffusion tensor imaging in mild cognitive impairment and Alzheimer's disease. Neurobiol Aging 32, 2322.e5-2322.e18. doi: 10.1016/j.neurobiolaging.2010.05.019 
Sheline, Y. I., and Raichle, M. E. (2013). Resting state functional connectivity in preclinical Alzheimer's disease. Biol. Psychiatry 74, 340-347. doi: 10.1016/j.biopsych.2012.11.028

Shimada, H., Ataka, S., Takeuchi, J., Mori, H., Wada, Y., Watanabe, Y., et al. (2011). Pittsburgh Compound B-negative dementia-a possibility of misdiagnosis of patients with non-Alzheimer disease-type dementia as having AD. J. Geriatr. Psychiatry Neurol. 24, 123-126. doi: 10.1177/0891988711409410

Shipley, S. M., Frederick, M. C., Filley, C. M., and Kluger, B. M. (2013). Potential for misdiagnosis in community-acquired PET scans for dementia. Neurol. Clin. Pract. 3, 305-312. doi: 10.1212/CPJ.0b013e318296f2df

Silverman, D. H., Small, G. W., Chang, C. Y., Lu, C. S., Kung De Aburto, M. A., Chen, W., et al. (2001). Positron emission tomography in evaluation of dementia: regional brain metabolism and long-term outcome. JAMA 286, 2120-2127. doi: 10.1001/jama.286.17.2120

Small, G. W., Kepe, V., Ercoli, L. M., Siddarth, P., Bookheimer, S. Y., Miller, K. J., et al. (2006). PET of brain amyloid and tau in mild cognitive impairment. $N$. Engl. J. Med. 355, 2652-2663. doi: 10.1056/NEJMoa054625

Sperling, R. A., Aisen, P. S., Beckett, L. A., Bennett, D. A., Craft, S., Fagan, A. M., et al. (2011). Toward defining the preclinical stages of Alzheimer's disease: recommendations from the National Institute on Aging-Alzheimer's Association workgroups on diagnostic guidelines for Alzheimer's disease. Alzheimers Dement. 7, 280-292. doi: 10.1016/j.jalz.2011. 03.003

Stomrud, E., Hansson, O., Blennow, K., Minthon, L., and Londos, E. (2007). Cerebrospinal fluid biomarkers predict decline in subjective cognitive function over 3 years in healthy elderly. Dement. Geriatr. Cogn. Disord. 24, 118-124. doi: $10.1159 / 000105017$

Sutphen, C. L., Jasielec, M. S., Shah, A. R., Macy, E. M., Xiong, C., Vlassenko, A. G., et al. (2015). Longitudinal cerebrospinal fluid biomarker changes in preclinical Alzheimer disease during middle age. JAMA Neurol. 72, 1029-1042. doi: 10.1001/jamaneurol.2015.1285

Valcárcel-Nazco, C., Perestelo-Pérez, L., Molinuevo, J. L., Mar, J., Castilla, I., and Serrano-Aguilar, P. (2014). Cost-effectiveness of the use of biomarkers in cerebrospinal fluid for Alzheimer's disease. J. Alzheimers Dis. 42, 777-788. doi: 10.3233/JAD-132216

Villemagne, V. L., Pike, K. E., Darby, D., Maruff, P., Savage, G., Ng, S., et al. (2008). Abeta deposits in older non-demented individuals with cognitive decline are indicative of preclinical Alzheimer's disease. Neuropsychologia 46, 1688-1697. doi: 10.1016/j.neuropsychologia.2008.02.008

Vos, S. J., Xiong, C., Visser, P. J., Jasielec, M. S., Hassenstab, J., Grant, E. A., et al. (2013). Preclinical Alzheimer's disease and its outcome: a longitudinal cohort study. Lancet. Neurol. 12, 957-965. doi: 10.1016/S1474-4422(13)70194-7

Wang, Z., Das, S. R., Xie, S. X., Arnold, S. E., Detre, J. A., and Wolk, D. A. (2013). Arterial spin labeled MRI in prodromal Alzheimer's disease: a multi-site study. Neuroimage Clin. 2, 630-636. doi: 10.1016/j.nicl.2013.04.014

Wierenga, C. E., Hays, C. C., and Zlatar, Z. Z. (2014). Cerebral blood flow measured by arterial spin labeling MRI as a preclinical marker of Alzheimer's disease. J. Alzheimers Dis. 42(Suppl. 4), S411-S419. doi: 10.3233/JAD-141467

Wolk, D. A., and Detre, J. A. (2012). Arterial spin labeling MRI: an emerging biomarker for Alzheimer's disease and other neurodegenerative conditions. Curr. Opin. Neurol. 25, 421-428. doi: 10.1097/WCO.0b013e328354ff0a

Yeo, J. M., Waddell, B., Khan, Z., and Pal, S. (2015). A systematic review and metaanalysis of ${ }^{18} \mathrm{~F}$-labeled amyloid imaging in Alzheimer's disease. Alzheimers Dement. 1, 5-13. doi: 10.1016/j.dadm.2014.11.004

Zetterberg, H., Skillbäck, T., Mattsson, N., Trojanowski, J. Q., Portelius, E., Shaw, L. M., et al. (2016). Association of cerebrospinal fluid neurofilament light concentration with Alzheimer disease progression. JAMA Neurol. 73, 60-67. doi: 10.1001/jamaneurol.2015.3037

Zhang, S., Smailagic, N., Hyde, C., Noel-Storr, A. H., Takwoingi, Y., McShane, R., et al. (2014). (11)C-PIB-PET for the early diagnosis of Alzheimer's disease dementia and other dementias in people with mild cognitive impairment (MCI). Cochrane Database Syst. Rev. 7:CD010386. doi: 10.1002/14651858.CD010386.pub2

Conflict of Interest Statement: The author declares that the research was conducted in the absence of any commercial or financial relationships that could be construed as a potential conflict of interest.

Copyright (๑) 2018 Khan. This is an open-access article distributed under the terms of the Creative Commons Attribution License (CC BY). The use, distribution or reproduction in other forums is permitted, provided the original author(s) and the copyright owner are credited and that the original publication in this journal is cited, in accordance with accepted academic practice. No use, distribution or reproduction is permitted which does not comply with these terms. 